\title{
Cannabis and Lung Health: Does the Bad Outweigh the Good?
}

\author{
Alan G. Kaplan (D
}

Received: July 22, 2021 / Accepted: August 12, 2021 / Published online: October 25, 2021

(C) The Author(s) 2021

\section{ABSTRACT}

Cannabis use is growing, with multiple medical 'indications' and approval for recreational use in many countries. This article will review some of the respiratory complications to cannabis use, which include lung function changes, lung destruction, increased risk of lung and head and neck cancer, and others. These are mostly related to smoking, and the co-administration of nicotine makes the risks a bit difficult to measure. However, with many reports of EVALI, electronic vaping-associated lung injury, being related to cannabis coadministration, it appears that the safest administration of cannabis, as far as lung health, is orally.

Keywords: Lung function; Cannabis; THC; CBD; Asthma; COPD; Lung cancer; Pneumothorax; Respiratory

Supplementary Information The online version contains supplementary material available at https:// doi.org/10.1007/s41030-021-00171-8.

A. G. Kaplan $(\bowtie)$

Family Physician Airways Group of Canada, Respiratory Effectiveness Group, Primary Care Respiratory Research, OPRI, local LHIN Pulmonary Rehabilitation Clinics, University of Toronto, 7335

Yonge Street, Thornhill, Toronto, ON L3T 2B2, Canada

e-mail: for4kids@gmail.com

\section{Key Summary Points}

Evidence collection for cannabis effect on the lung is complicated by issues of accurately understanding the dose given, the concomitant use of nicotine making the effect of the cannabis difficult to assess, and the evidence mostly including only THC while CBD is getting more common to be used for medicinal purposes.

Smoking THC is associated with worsening respiratory symptoms of cough or sputum, wheezing, and shortness of breath, increased incidence of acute bronchitic episodes or clinic visits for acute respiratory illness.

Cannabis leads to hyperinflation and increased large airway resistance, with little evidence of airflow obstruction (cf. nicotine smoking, which causes airflow obstruction).

The association of smoking cannabis to lung cancer risk is not clear. 
Multiple case reports show a relationship of cannabis smoking to multiple respiratory conditions including cannabis-induced complications including aspergillosis, hemoptysis, emphysema and secondary pneumothorax, hypersensitivity pneumonitis, eosinophilic pneumonitis, ARDS, vanishing lung syndrome, and emphysema.

\section{DIGITAL FEATURES}

This article is published with digital features, including a video abstract, to facilitate understanding of the article. To view digital features for this article go to https://doi.org/10.6084/ m9.figshare.16622608.

\section{INTRODUCTION}

Cannabis use is growing, according to the United Nations, with 158.8 million people around the world using marijuana-more than $3.8 \%$ of the planet's population. Interestingly, their 2019 stats suggest that globally between 4 and $9.1 \%$ of children aged $15-16$ years old around the world use cannabis [1]. In 2018, 14\% of Canadians aged 15 years or older reported cannabis use in the past 3 months, with $40 \%$ of these individuals reporting daily use [2]. Over 94 million people in the US have admitted using it at least once [3]. In December 2020, the United Nations voted to remove cannabis for medicinal purposes from a category of the world's most dangerous drugs [4]. Many countries have legalized its use, leading to the attitude that if it is legal, it must be safe. The myriad of benefits claimed to be had by medical cannabis make it an intriguing choice for physicians and patients. These include potential benefits [5] including chronic pain, especially neuropathic pain [6], spasticity associated with multiple sclerosis, nausea, posttraumatic stress disorder, cancer, epilepsy, cachexia, glaucoma, HIV/AIDS, and degenerative neurological conditions, chemotherapy-induced nausea and vomiting, anorexia and weight loss associated with HIV, irritable bowel syndrome, epilepsy, spasticity, Tourette syndrome, amyotrophic lateral sclerosis, Huntington's disease, Parkinson's disease, dystonia, dementia, traumatic brain injury, addiction, anxiety, depression, sleep disorders, posttraumatic stress disorder, and schizophrenia and other psychoses. The business side of this is staggering, with 2020 estimates that the cannabis industry was worth $\$ 16.1$ billion in the United States and $\$ 19.6$ billion worldwide. Positive impacts from the national legalization of recreational cannabis use in Canada beyond recreational use and relief of medical issues include increased tax revenue for the Canadian economy, decreased black market activity, and reduced criminal charges (which disproportionately affect marginalized populations).

\section{METHODS}

In 2018, the Canadian Thoracic Society (CTS) formed a group to create a guideline paper on cannabis and respiratory health. Unfortunately, due to the pandemic, this has been delayed. A search of papers was done, and articles were prepared for six PICO questions and reviewed by the panel. I used these papers which were vigorously searched and reviewed as the basis of my evidence and separately searched for any unanswered questions. PICO [7] stands for Population/Intervention/Compare/Outcome. I was subsequently requested to publish on this topic, which I felt would be useful and appropriate as the CTS process had been so delayed and the topic is of such controversy. This article is based on previously conducted studies and does not contain any new studies with human participants or animals performed by any of the authors.

There are many non-respiratory risks of cannabis use [8]. In short-term use, these include impaired short-term memory, impaired motor coordination, risk of injury, e.g., driving, altered judgement, e.g., sexual behaviors leading to risk of STDs, paranoia, and psychosis (usually in higher doses).

In long-term or heavy use, reported issues include addiction (risk is $9 \%$ overall, but $17 \%$ 
for those who start use in adolescence, and up to $50 \%$ in those who are daily users), altered brain development, poor educational completion/outcomes, cognitive impairment (IQ levels impaired with frequent use during adolescence), diminished long-term life satisfaction, increased risk of psychotic disorders such as schizophrenia.

As such, legalization in countries such as Canada needs to take this into account, especially in its use in vulnerable groups, such as children and youth, pregnant women, individuals with mental illness, individuals with low socio-economic status, and indigenous populations [9].

In Canada [10], data show that smoking (79\%) was the most common method of cannabis consumption reported by people who used cannabis over the previous 12 months, a decrease from 2019 (84\%). Other methods of consumption were: eating it in food (52\%), an increase from 2019 (46\%), vaporizing using a vape pen or e-cigarette (24\%), a decrease from 2019 (27\%), and vaporizing using a vaporizer (12\%), a decrease from 2019 (15\%). Onset of action is much quicker when taken by the inhaled route, making it the preferred route for many patients, especially when used recreationally. That being said, for conditions like pain, PTSD, and epilepsy, the oral slower onset but longer duration in products like oils are a realistic alternative. I will deal with studies of inhaled cannabis only, with the preponderance being smoked, but will also discuss vaporization and other methods of smoking like using a waterpipe.

This review is to be based on the respiratory effects of cannabis use. Risks are confounded by the co-administration of nicotine in smoking, often making it hard to separate the actual risk of the cannabis from the tobacco.

\section{DIFFICULTY IN ANALYSIS OF STUDIES}

Because of the frequent co-administration of tobacco in people who smoke cannabis, it is difficult to separate the effects of each substance. Smoking tobacco is already recognized to cause symptoms of cough, sputum, chronic bronchitis, wheezing, and shortness of breath. Tobacco smoking leads to airway inflammation and damage to small and large airways causing COPD and to the alveoli causing emphysema. Spirometric measures lead to a progressive loss of lung function as measured by forced expiratory volume in $1 \mathrm{~s}$ (FEV1) and FEV1 divided by forced vital capacity (FVC) - FEV1/FVC ratio. Pulmonary function testing shows air-trapping within the lungs, measured with total lung capacity (TLC) or residual volume (RV) or the ratio $\mathrm{RV} / \mathrm{TLC}$ ) as seen on chest X-ray (CXR).

Studies are also limited due to the difficulties in measuring the amount of cannabis used. As a rule, one joint-year is defined as 365 joints smoked. Both the size of a joint and dosing frequency are not reproducible and often selfreported, making reproducibility difficult. Selfreported joint-years to quantify use may be inaccurate, owing to the legality of cannabis use, recall bias, and alteration of behavior by its observation [11, 12].

Cannabis can be smoked in many different ways, which will also alter the net dose effect. As an example, using a water bong will potentially decrease the concentration of inhaled carcinogenic compounds [13]. Using a vaporizer to inhale cannabis rather than combusting it in smoke may reduce pulmonary complications, but the recent epidemic of EVALI [14] is of significant concern for more acute lung complications [15].

Cannabis and tobacco tend to be smoked differently. Typically, cannabis is smoked without a filter, to a shorter butt length, and the smoke is at a higher temperature. Furthermore, cannabis smokers (cf. tobacco alone) take larger puffs, inhale more deeply, hold their breath for longer (about four times longer), and perform a Valsalva maneuver at maximal breath-hold [16]; this leads to differing lung exposure and deposition of components as well as creating the potential for barotrauma $[17,18]$.

Cannabis is not one drug. There are multiple components including THC (delta-9-tetrahydrocannabinol), CBD (cannabidiol), and terpenes all in differing combinations in different preparations. Most studies have been done with THC and are older. CBD treatment decreased 
the inflammatory and remodeling processes in the mouse model of allergic asthma [19]. Newer formulations of THC are of a much higher concentration due to the demand for rapid effect. As such, the conclusions from the THC studies may not be referable to current available strains.

Cannabis smoking via combustion, even without cigarette smoking [20], has been associated with respiratory symptoms, chronic bronchitis, changes in lung function testing, risk of developing COPD, worsening of asthma and COPD, bullous disease, and lung and head and neck cancer due to exposure to carcinogens [21], cardiovascular complications, allergy, and respiratory infections $[22,23]$. These elevated risks are presumed to be reduced in methods of consumption that do not include combustion (e.g., vaping, edibles); however, the relative safety of these methods is as yet unknown. I will break down some of the risks in the upcoming sections.

\section{LUNG FUNCTION}

\section{Acute Effects of Smoked Cannabis}

Cannabis had been used as an asthma treatment since the 19th century [24], with subsequent proof of some bronchodilator effects. Comparatively, smoking a single tobacco cigarette causes acute bronchoconstriction, which has been attributed to an irritant effect of the smoke leading to cholinergically mediated reflex bronchospasm [25]. In contrast, smoking a single "joint" of marijuana (2\% THC) created acute bronchodilation in healthy subjects [26], and in patients with mild asthma, with a rapid onset and duration of at least $2 \mathrm{~h}$ [27]. This effect, which persisted for at least $1 \mathrm{~h}$, was due to the THC content of the "joint" because the effect was not seen when the THC was extracted but was subsequently reproduced after the "joint" was spiked with synthetic THC [28, 29]. Other studies did not show any bronchodilator effect [30]. Overall, while there may be some bronchodilator effects, they are likely negated by the paradoxical bronchospasm that also occurs with inhalation of combusted materials [31].

\section{Chronic Use of Smoked Cannabis Effects}

Old data suggested a possible bronchodilator effect with acute THC use. This has been confirmed [32], but is less than salbutamol, and is lost over time with the effects of combustion when smoked.

In a structured review of cannabis on lung function [23], there was variability in the findings in cannabis-only smokers from a reduction in the FEV1/FVC ratio to no change reported. In a population-based cohort in Dunedin, New Zealand, in a study of 1937 patients, there was no association between chronic marijuana use and change in FEV1 or FEV1/FVC at age 32 but there was an increased FVC [33]. In a cross-sectional study of 7716 US adults from the National Health And Nutrition Examination Study cohort, Kempker [34] showed no effect on FEV1/FVC up to 20 joint-years, but in those with greater than 20 joint-years there was a 2.1fold risk for FEV1/FVC ratio $<70 \%$, accounted for by a significant increase in FVC and no significant reduction in FEV1. These results suggests that while the FEV1/FVC decreases by $\sim 1.5 \%$ in most chronic users, this may not relate to a reduction in FEV1 but to an increase in FVC. These findings represent a major difference in the effects of cannabis compared to the effects of tobacco smoking [23]. It may be quite different in those smoking both cigarettes and cannabis but no additive adverse effects of marijuana on lung function (cf. symptoms) when smoked along with tobacco have been reported [22].

Studies of the pathophysiology of cannabis smoke have shown related large airway epithelial damage, edema, erythema, and increased secretions with goblet cell hyperplasia, loss of ciliated epithelium, and squamous metaplasia on biopsy. There is additive bronchial epithelial damage in combined cannabis and tobacco smokers [35].

In summary, there are different and distinct patterns of lung changes [33] between cannabis and tobacco smokers, indicating different physiologic consequences for the lungs. Cannabis leads to hyperinflation and increased large airway resistance, with little evidence of airflow obstruction or impairment of gas 
transfer, whereas tobacco was associated with airflow obstruction, gas trapping, and lower transfer factors.

\section{RESPIRATORY SYMPTOMS}

Patients with chronic cannabis smoking show an increased prevalence of chronic cough or sputum, wheezing and shortness of breath, increased incidence of acute bronchitic episodes, or clinic visits for acute respiratory illness. Knowing that tobacco smoking causes these as well, there have been studies done to compare to cannabis-only smokers. In a study from Los Angeles [36], daily cannabis smokers were compared to tobacco-only smokers, combined smokers, and non-smokers. In the smokers of marijuana alone, tobacco alone, or marijuana plus tobacco, the prevalence of chronic cough (18-24\%), sputum production (20-26\%), wheezing for at least 3 weeks/year (25-37\%), and at least two prolonged episodes of acute bronchitis during the previous 3 years (10-14\%) were significantly higher than in the non-smokers. However, there did not seem to be any additive effect, as there were no differences between the three active comparator groups of smokers of any kind. In a similar study in Tucson Arizona [37], chronic cough was less common in marijuana-only smokers than tobacco smokers, but the effects of combined smoking of marijuana and tobacco on cough and sputum appeared to be additive. In a 2-year follow-up study from Kaiser Permanente of 452 daily marijuana-only smokers and 450 non-smokers, there was a significant increase in outpatient visits for respiratory illnesses among the marijuana smokers (RR, 1.19; 95\% CI 1.01-1.41) [38]. In a Dunedin New Zealand cohort, they corrected for tobacco use and found that early morning sputum production, wheezing apart from colds, nocturnal awakenings with chest tightness, and exercise-induced shortness of breath were increased among the cannabis-dependent subjects by $144 \% \quad(P=$ $0.01), 61,65$, and $72 \%$, respectively, compared with non-smokers [39]. In another New Zealand study of adult residents of Wellington, New Zealand [40], the odds ratios $(95 \% \mathrm{CI})$ for the association of cough with marijuana smoking and tobacco smoking were 1.5 (1.1-1.7) and 1.9 (1.4-2.6), respectively, and of chronic sputum production were $2.0(1.4-2.7)$ and $1.6(1.2-2.2)$, respectively. There was no evidence of any additive effects of marijuana and tobacco, consistent with the findings in the Los Angeles study. In a survey of older adults ( $>40$ years) residing in Vancouver, Canada, as part of the Burden of Obstructive Lung Diseases (BOLD) study [41], the odds ratio (OR) for chronic respiratory symptoms was not increased among the $49 \%$ of respondents who reported ever using marijuana alone and importantly the concurrent use of marijuana and tobacco was associated with a higher OR for respiratory symptoms (OR, 2.59; 95\% CI 1.58-3.62) compared to smoking tobacco alone. Cannabis in addition to tobacco contributed to a diagnosis of COPD at an earlier age with a trend to poorer lung function [42].

As such, there is a lot of conflicting evidence, which highlights the difficulties in these studies, with difficulties in measuring the amount of cannabis actually used due to self reporting of smoking frequency and cannabis dose. That being said, there seems to be a significant association of marijuana use with symptoms of chronic bronchitis that may be comparable to or less than that of tobacco smoking alone. Similarly, evidence is mixed regarding the possibility of additive or synergistic effects of combined smoking of marijuana and tobacco on chronic respiratory symptoms. Looking at this from the point of cessation of cannabis smoking in cannabis-only smokers, there is an improvement of pre-existing respiratory symptoms of chronic bronchitis [43] with symptoms in the quitters being reduced to levels similar to those in never-users [44].

\section{LUNG CANCER RISK}

There is obvious concern for cannabis smoking to increase lung cancer risk, as tobacco smoking is the major cause of lung cancer [45], and marijuana and tobacco smoke both contain many of the potent carcinogens [46]. In addition, as marijuana smoking is usually associated 
with deeper inhalation, longer breath-holding times, use of unfiltered marijuana cigarettes ("joints") with a potential for greater delivery of tar to the lungs [47], and the marijuana smoke being even more cytotoxic and mutagenic $[48,49]$ in comparison with tobacco smoking. Bronchial biopsies have demonstrated that marijuana users show not only manifest airway inflammation but also histopathological and/or molecular changes indicative of precancerous bronchial activity [50, 51]. Endobronchial biopsies from habitual marijuana-only smokers reveal widespread histopathologic alterations that are recognized as precursors to the subsequent development of malignancy [52], such as squamous cell metaplasia and cellular atypia, comparable to those observed in biopsies from tobacco-only smokers [53].

Despite this, epidemiological studies have not always found a definite association. Casecontrolled studies and cohort studies have not shown an increased risk [54, 55], while other epidemiological studies have reported associations with lung cancer with heavier marijuana use. For example, a 40-year longitudinal cohort study in 49,321 Swedish conscripts found that those who smoked cannabis $>50$ times had a twofold risk of developing lung cancer [56].

Despite the obvious biologic plausibility, the lack of consistent epidemiological evidence might be due to methodological issues including lack of cohort follow-up time into older adulthood (when lung cancer usually becomes clinically manifest), small sample sizes, selection and recall biases, and lack of adjustment for tobacco use in the statistical modeling. However, biologic plausibility can go both ways. There have been anti-tumor effects of cannabinoids in animal [57] and cell culture [58, 59] models.

Multiple case-controlled [60, 61] or cohort $[62,63]$ studies have shown no evidence of either lung or upper-airway cancer increase [64], especially after being controlled for tobacco use. An early case-control study in New Zealand [65] of marijuana use and lung cancer risk that included only 79 cancer-case subjects and 324 matched control subjects was published in 2008. It only showed that an increased risk was noted among the 14 case subjects and four control subjects in the highest tertile of marijuana use (RR, 5.7; 95\% CI 1.5-21.6), corresponding to a life-time history of more than 10.5 joint-years (number of joints per day times number of years smoked, but the numbers were quite small of this group).

In a New Zealand registry trial [66] looking at the risk of head and neck cancers, an increased risk of cancer was found with increasing tobacco use, alcohol consumption, and decreased income, but not increasing cannabis use. The highest tertile of cannabis use $(>8.3$ joint-years) was associated with a non-significant increased risk of cancer (relative risk $=1.6$, 95\% confidence interval, 0.5-5.2) after adjustment for confounding variables. The authors concluded that cannabis use did not increase the risk of head and neck cancers.

Consecutive patients with a newly diagnosed head and neck cancer were prospectively enrolled between 2011 and 2015 in a tertiary center in Hamilton, Ontario [67]. Cannabis users and controls were compared using standard modes of comparison. No significant differences between cannabis users and controls were observed except that cannabis users were more likely to develop primary oropharyngeal cancer $(p=0.0046)$. Two of $59(3.4 \%)$ cannabis users developed a second primary cancer, in comparison to 23 of 454 (5.1\%) non-cannabis users. As such, cannabis use (different than tobacco) did not seem to induce an increase in a second primary head and neck cancers.

A study done in Northern Africa [68] looking at 636 cases of nasopharyngeal carcinoma found a higher risk of nasopharyngeal carcinoma with cannabis smokers adjusted for tobacco in those with ever-cannabis smoking and those with lifetime high-dose cannabis smoking (OR, 2.62; 95\% CI 1.00-6.86). It did not, however, include cannabis-only smokers, which could limit its relevance.

Studies have also looked at non-respiratory cancers, with no definitive answers but some possible relationships. In a US study following cannabis smokers for a mean of 8.6 years, the findings showed that among non-smokers of tobacco cigarettes, ever having used marijuana was associated with increased risk of prostate cancer $\quad(\mathrm{RR}=3.1, \quad$ CI 1.0-9.5) and nearly 


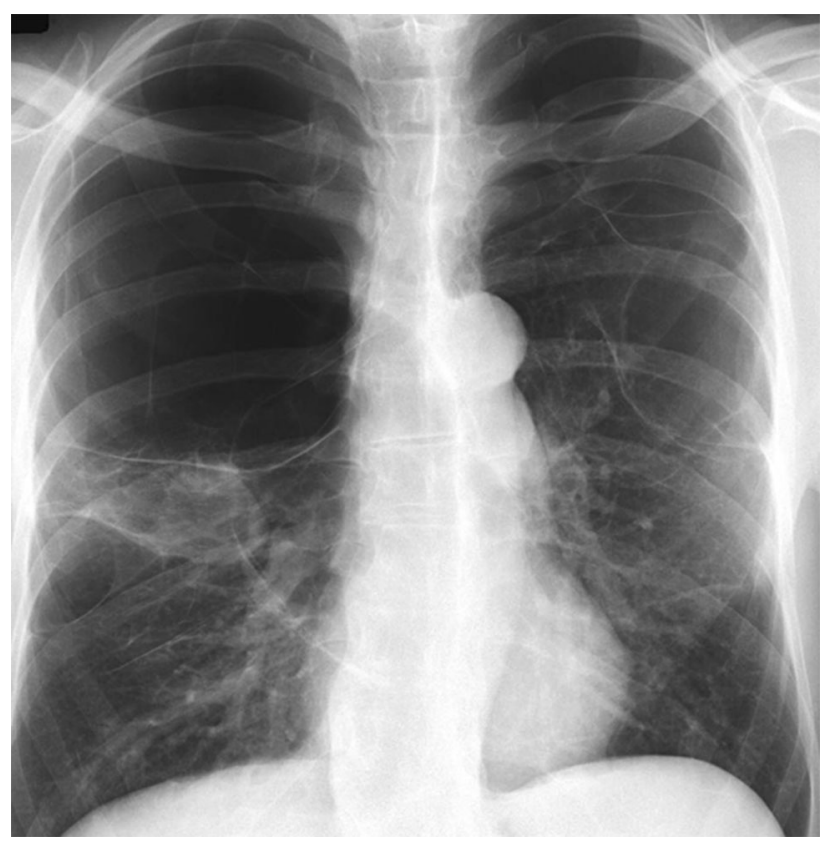

Fig. 1 Image of 'vanishing lung'

significantly increased risk of cervical cancer $(\mathrm{RR}=1.4$, CI 1.0-2.1). Their conclusion was that in non-smokers of tobacco cigarettes, marijuana use might affect certain site-specific cancers [41].

\section{ASTHMA}

There seems to be an increased risk of exacerbations in asthmatics who smoke cannabis. In an emergency room study [69] of patients presenting with an asthma exacerbation looking at those with cannabis use, they reviewed patients with at least one exacerbation in the last year and reduced lung function (FEV1 $<70 \%)$. There were more total exacerbations in the next 3 months (59 vs. 29\%) in cannabis smokers compared with non-cannabis smokers as well as a higher rate of exacerbations (3.98 vs. 1.96/ year).

\section{COPD}

As part of the Burden of Obstructive Lung Disease (BOLD) Initiative looking at a random sample of people over 40 in Vancouver, Canada, a questionnaire about tobacco and cannabis smoking was followed by spirometry [70]. Compared with non-smokers, tobacco-only smokers (but not cannabis-only smokers) experienced more frequent respiratory symptoms (odds ratio [OR] 1.50, 95\% CI 1.05-2.14) and were more likely to have COPD (OR 2.74, 95\% CI 1.66-4.52). Concurrent use of both cannabis and tobacco was associated with increased risk (even adjusted for age, asthma, and comorbidities) of respiratory symptoms (OR 2.39, 95\% CI 1.58-3.62) and COPD (OR 2.90, 95\% CI 1.53-5.51) if the lifetime dose of marijuana exceeded 50 marijuana cigarettes. The risks of respiratory symptoms and of COPD seemed to be related to a synergistic interaction between marijuana and tobacco, but did not occur in cannabis-only smokers. This may be related to the relative amounts of actual cigarettes used in the cannabis-only smokers being so much less, however.

\section{ALLERGIC REACTIONS}

Allergic reactions to the weed itself as well as cross reactivity to other allergens such as plant foods in the "cannabis-fruit/vegetable syndrome 
[71]" are an underappreciated issue [72]. Hypersensitivity reactions [73] to MJ exposure and respiratory, contact, and ingestion can range from mild to severe, including anaphylaxis. This can be a result of protein allergens of the flower, fungal sensitization [74], or other components such as mold and pesticides [75]. While skin testing for the flower extracts (e.g., Cannabis sativa) are possible, these other factors can complicate the diagnosis.

\section{OTHER LUNG COMPLICATIONS}

Multiple case reports have been published of patients developing bullous disease from lung destruction associated with inhaled cannabis. Unfortunately for epidemiologic review, the cases are often those with combined inhalation of cannabis and cigarette smoke. Cases of large sometime multiple bullae, often with air fluid levels lead to scary looking radiographs and bad patient outcomes [76]. This is not something reported with tobacco alone, so the cannabis must be the causal factor.

Other case reports of cannabis-induced complications include hemoptysis [77], emphysema and secondary pneumothorax [78], hypersensitivity pneumonitis [79], eosinophilic pneumonitis [80], ARDS, vanishing lung syndrome (Fig. 1) [81], and emphysema [82, 83].

It is possible that the hyperinflation seen in cannabis users in addition to the Valsalva maneuver often used with inhalation may be involved in the cases of spontaneous pneumothorax and/or pneumomediastinum and of the peripheral apical lung bullae [50] that have been reported in isolated cases of marijuana smokers.

In addition, cases of aspergillosis have been reported [84] in cannabis smokers. Smoking marijuana affects the lungs structurally but may also affect them immunologically, by affecting alveolar macrophages [85]. This may predispose marijuana users to pulmonary infection. Both tobacco and marijuana are commonly contaminated with fungi, and serology from marijuana smokers exhibits evidence of Aspergillus exposure [86]. It remains to be seen whether fungal spores survive the burning process, leading to etiology related to inhalation and even potentially just handling.

\section{CARDIOVASCULAR RISK}

Marijuana use, mechanistically due to an increase in catecholamines, cardiac workload, and carboxyhemoglobin levels as well as episodes of significant postural hypotension, may trigger an increase in the risk of myocardial infarction, especially in older patients at risk for cardiovascular disease. In a study of 124 patients admitted for acute myocardial infarction [87] who reported marijuana use and controlled for other triggers, there was a 4.8 -fold increase in the risk of myocardial infarction (95\% confidence interval [CI] 2.4-9.5, $p=$ 0.001 ) in the first hour following marijuana use as compared with periods of non-use.

Older data compared smoking a single cannabis cigarette to a tobacco cigarette. Smoking a cannabis cigarette showed an increase in the resting measurement of systolic blood pressure times heart rate of $54 \%$, increased the venous carboxyhemoglobin level, and decreased the exercise time until angina by $50 \%$ in ten patients with angina pectoris. Compare that to the smoking of a single high-nicotine cigarette which increased the resting measurement of systolic blood pressure times heart rate by $36 \%$, also increased the venous carboxyhemoglobin level, and decreased the exercise time until angina by $23 \%$. As such, smoking either cannabis or high-nicotine cigarettes will decrease exercise performance until angina by increasing myocardial oxygen demand and by decreasing myocardial oxygen delivery. However, smoking one marijuana cigarette decreased the exercise time until angina greater than smoking a single high-nicotine cigarette $(p<0.001)$ [88].

Arrhythmias such as atrial fibrillation have been described in case studies, with other cases of fatal ventricular arrhythmias [89-92] also being described, postulated due to triggering of the Purkinje fibers or coronary vasospasm.

Transient cerebral ischemic events and strokes following marijuana use have also been reported [93-95]. Cerebral vasospasm is 
postulated from a series of three patients with stroke symptoms and normal angiograms [96].

'Cannabis arteritis' [97] describes peripheral vascular consequences in high-dose marijuana users [32]. Disdier [98] described a series of ten patients who developed subacute and progressive ischemia of distal upper and lower extremities leading to tissue necrosis and gangrene [99].

\section{OTHER INHALATIONAL METHODS OF INGESTION OTHER THAN SMOKING}

For the most part, I have been discussing smoking cannabis. Clearly ingestion of cannabis orally is not going to have adverse respiratory effects but with most studies being done on whole marijuana smoke, it is difficult to determine if the currently available data is applicable to these newer products [100]. However, cannabis is inhaled in other vehicles including vaporizers, hookah (water pipe), and electronic cigarettes.

Waterpipe smoking tobacco has had claims of safety based on the lack of combustion and the water filter. These have been disproved, with CO levels shown to be higher than in cigarettes [101] (possibly related to the charcoal used to heat the tobacco; this is found in both tobacco and non-tobacco hookah smokers, which shows that the absence of tobacco does not make hookah smoking safe) and the fact that water does not filter out the harmful chemicals [102]. There is a paucity of data of smoking cannabis in a hookah, but safety cannot be assumed.

Vaporizers work by running air across the cannabis without actually burning or combusting it. With some types, the patient must inspire to allow the hot air to pass through the cannabis, which will expose the lungs also to the extreme heat and the risk of possible thermal damage. Other devices avoid the thermal exposure by blowing air into a different part of the vaporizer away from the heating element. The vaporizer contains cannabis vaporizer and thus raises cannabinoid levels but not exhaled CO levels. Switching from combustion to a vaporizer [103] has shown that users with respiratory irritation improved symptoms and lung function. As such, vaporizers may be of some value for cannabis users who want to avoid pulmonary problems and certainly offer a more rapid onset than do edibles. That being said, ensuring the correct vehicle is important with case reports of lung damage due to vaporizing cannabis oil [104].

Switching to vaporizer is therefore considered a safer method to using cannabis than smoking it [105]. Switching from smoking to vaping cannabis [106] has mostly just shown a reduction in symptoms of chronic bronchitis related to the smoking. Clearly removing smoking tobacco from the equation will also induce benefits. So, with some modest respiratory health benefits of vaping compared to smoking cannabis, this is likely the preferred delivery mechanism for those patients with chronic respiratory illnesses like asthma and COPD who wish to use cannabis for medicinal purposes [107] and require more rapid onset of effect than non-respiratory delivery systems like oral and topical.

EVALI or e-cigarette or vaping use-associated lung injury was first described in 2019 and led to a large reporting of cases. After publication of the problem, fortunately cases have declined sharply since August 2019 [108]. National and state data from patient reports and product sample testing show tetrahydrocannabinol (THC)-containing e-cigarette, or vaping, products, particularly from informal sources like friends, family, or in-person or online dealers, are linked to most EVALI cases and play a major role in the outbreak. Vitamin $\mathrm{E}$ acetate is strongly linked to the EVALI outbreak. One theory is that the vitamin E used as a thickening agent or to dilute THC oil in vape cartridges to make it go further was a part of the pathogenesis. Vitamin E acetate has been found in product samples tested by the FDA and state laboratories and in patient lung fluid samples tested by CDC from geographically diverse states. Vitamin $\mathrm{E}$ acetate has not been found in the lung fluid of people that do not have EVALI. It is now recommended to not add vitamin $\mathrm{E}$ acetate to any e-cigarette products, and the incidence of EVALI has thankfully fallen 
significantly, to the point that the disease may be associated with the vitamin $\mathrm{E}$ and not the cannabis, but this is not yet completely clear. The bottom line is: vaping cannabis may not be a recipe for safe use!

\section{CONCLUSIONS}

Cannabis inhaled by combustion clearly leads to significant respiratory effects including changes in lung function (hyperinflation) and symptoms. The relationship with lung cancer is less clear. The equivalence of cannabis smoke exposure to cigarette smoke is also unclear, but the relationship shown in an earlier study still sounds like the best estimate I have seen; i.e., the 1:2.5-5 dose equivalence between cannabis joints and tobacco cigarettes for adverse effects on lung function [107].

For those purporting the benefits of cannabis, I am not saying it should not be used. Clearly, pregnant women and people under the age of 25 should be avoiding exposure due to potential adverse effects on developing brains and perhaps the risk of EVALI if vaporized in an electronic cigarette. In addition, almost all of the data collected are related to THC use, and with CBD being often recommended for management of multiple conditions, this is clearly an area in which research is required. That being said, when used, cannabis should be used safely without causing respiratory harm and should not be used combusted or combined with tobacco in a cigarette.

\section{ACKNOWLEDGEMENTS}

Funding. No funding or sponsorship was received for this study or publication of this article.

Authorship. All named authors meet the International Committee of Medical Journal Editors (ICMJE) criteria for authorship for this article, take responsibility to the integrity of the work as a whole, and have given their approval for this version to be published.
Disclosures. The author is a member of a speakers' bureau or advisory board for Astra Zeneca, Behring, Boehringer Ingelheim, Covis, Cipla, GSK, Novartis, Pfizer, Purdue, Sanofi, Spectrum, Teva, Trudel.

Compliance with Ethics Guidelines. This article is based on previously conducted studies and does not contain any new studies with human participants or animals performed by any of the authors.

Open Access. This article is licensed under a Creative Commons Attribution-NonCommercial 4.0 International License, which permits any non-commercial use, sharing, adaptation, distribution and reproduction in any medium or format, as long as you give appropriate credit to the original author(s) and the source, provide a link to the Creative Commons licence, and indicate if changes were made. The images or other third party material in this article are included in the article's Creative Commons licence, unless indicated otherwise in a credit line to the material. If material is not included in the article's Creative Commons licence and your intended use is not permitted by statutory regulation or exceeds the permitted use, you will need to obtain permission directly from the copyright holder. To view a copy of this licence, visit http://creativecommons.org/licenses/by$\mathrm{nc} / 4.0 /$.

\section{REFERENCES}

1. https://www.unodc.org/unodc/en/data-and-analys is/wdr2021_annex.html. Accessed 24 June 2021

2. Statistics Canada (2018) National Cannabis Survey, first quarter 2018. Retrieved 29 Oct 2018 from: https://www150.statcan.gc.ca/n1/daily-quoti dien/180418/dq180418b-eng.htm.

3. https://www.drugfreeworld.org/drugfacts/marijua na/international-statistics.html

4. https://www.nytimes.com/2020/12/02/world/euro pe/cannabis-united-nations-drug-policy.html

5. The Health Effects of Cannabis and Cannabinoids: The Current State of Evidence and 
Recommendations for Research. https://www.ncbi. nlm.nih.gov/books/NBK425767/ Accessed 24 June 2021

6. Aviram J, Samuelly-Leichtag G. Efficacy of cannabisbased medicines for pain management: a systematic review and meta-analysis of randomized controlled trials. Pain Phys. 2017;20:E755-96.

7. https://libraryguides.nau.edu/c.php?g=665927\&p= 4682772, Accessed 9 Aug 2021

8. Volkow ND, Baler RD, Compton WM, Weiss SR. Adverse health effects of marijuana use. N Engl J Med. 2014;370(23):2219-27. https://doi.org/10. 1056/NEJMra1402309.

9. Windle SB, Wade K, Filion KB, Kimmelman J, Thombs BD, Eisenberg MJ. Potential harms from legalization of recreational cannabis use in Canada. Can J Public Health. 2019;110(2):222-6. https://doi. org/10.17269/s41997-018-00173-1.

10. Gov't of Canada. Canadian Cannabis Survey 2020: Summary. https://www.canada.ca/en/healthcanada/services/drugs-medication/cannabis/ research-data/canadian-cannabis-survey-2020summary.html. Accessed 24 June 2021

11. Cascini F, Aiello C, Di Tanna G. Increasing delta-9tetrahydrocannabinol (Delta-9-THC) content in herbal cannabis over time: systematic review and meta-analysis. Curr Drug Abuse Rev. 2012;5:32-40.

12. Potter DJ, Clark P, Brown MB. Potency of delta 9-THC and other cannabinoids in cannabis in England in 2005: implications for psychoactivity and pharmacology. J Forensic Sci. 2008;53:90-4.

13. Savaki HE, Cunha J, Carlini EA, Kephalas TA. Pharmacological activity of three fractions obtained by smoking cannabis through a water pipe. Bull Narc. 1976;28:49-56.

14. King B, Jones C, Baldwin G, Priss B. The EVALI and youth vaping epidemics - implications for public health. N Engl J Med. 2020;382:689-91. https://doi. org/10.1056/NEJMp1916171.

15. Outbreak of lung injury associated with the use of e-cigarette, or vaping, products. centre for diseases control and prevention. https://www.cdc.gov/ tobacco/basic_information/e-cigarettes/severelung-disease.html. Accessed 27 June 2021

16. Tashkin DP, et al. Tar, CO and delta 9THC delivery from the 1st and 2nd halves of a marijuana cigarette. Pharmacol Biochem Behav. 1991;40:657-61.

17. Wu TC, Tashkin DP, Djahed B, Rose JE. Pulmonary hazards of smoking marijuana as compared with tobacco. N Engl J Med. 1988;318:347-51.
18. Birrer RB, Calderon J. Pneumothorax, pneumomediastinum, and pneumopericardium following Valsalva's maneuver during marijuana smoking. NY State J Med. 1984;84:619-20.

19. Vuolo F, et al. Cannabidiol reduces airway inflammation and fibrosis in experimental allergic asthma. Eur J Pharmacol. 2019;843:251-9.

20. National Academies of Sciences, Engineering, and Medicine. The health effects of cannabis and cannabinoids: The current state of evidence and recommendations for research. Washington: The National Academies Press; 2017.

21. Moir D, Rickert WS, Levasseur G, Larose Y, Maertens R, White P. Desjardins SA comparison of mainstream and sidestream marijuana and tobacco cigarette smoke produced under two machine smoking conditions. Chem Res Toxicol. 2008;21(2): 494-502.

22. Tashkin D. Effects of marijuana smoking on the lung. Ann Am Thorac Soc. 2013;10(3):239-47.

23. Ribeiro 1, Ind P. Effect of cannabis smoking on lung function and respiratory symptoms: a structured literature review. Npj Prim Care Respir Med. 2016;26:16071. https://doi.org/10.1038/npjpcrm. 2016.71 .

24. Grinspoon L. Marijuana. Sci Am. 1969;221:17-25.

25. Nadel JA, Comroe JH Jr. Acute effects of inhalation of cigarette smoke on airway conductance. J Appl Physiol. 1961;16:713-6.

26. Tashkin DP, Shapiro BJ, Frank IM. Acute pulmonary physiologic effects of smoked marijuana and oral $\Delta$ 9-tetrahydrocannabinol in healthy young men. N Engl J Med. 1973;289:336-41.

27. Tashkin DP, Shapiro BJ, Frank IM. Acute effects of smoked marijuana and oral $\Delta 9$-tetrahydrocannabinol on specific airway conductance in asthmatic subjects. Am Rev Respir Dis. 1974;109:420-8.

28. Vachon L, Fitzgerald MX, Solliday NH, Gould IA, Gaensler EA. Single-dose effect of marijuana smoke: bronchial dynamics and respiratory center sensitivity in normal subjects. N Engl J Med. 1973;288: 985-9.

29. Tashkin DP, Shapiro BJ, Frank IM. Acute effects of marihuana on airway dynamics in spontaneous and experimentally induced bronchial asthma. In: Braude M, Szara S, editors. Pharmacology of marihuana. New York: Raven Press; 1976. p. 785-801.

30. Schwin R, Goodwin D, Hill S. Marihuana and tidal volume. JAMA. 1973;223(2):194-5. 
31. Calignano A, Katona I, Desarnaud F, Giuffrida A, La Rana G, Mackie K, Freund TF, Piomelli D. Bidirectional control of airway responsiveness by endogenous cannabinoids. Nature. 2000;408(2):96-101.

32. Williams W, Hartely JP, Graham JD. Bronchodilator effect of tetrahydrocannabinol administered by aerosol to asthmatic patients. Thorax. 1976;31:720.

33. Hancox RJ, et al. Effects of cannabis on lung function: a population-based cohort study. Eur Respir J. 2010;35:42-7.

34. Kempker JA, Honig EG, Martin GS. The effects of marijuana exposure on expiratory airflow. A study of adults who participated in the US National Health and Nutrition Examination Study. Ann Am Thorac Soc. 2015;12:135-41.

35. Fligiel SE, et al. Tracheobronchial histopathology in habitual smokers of cocaine, marijuana, and/or tobacco. Chest. 1997;112:319-26.

36. Tashkin DP, Coulson AH, Clark VA, Simmons M, Bourque LB, Duann S, Spivey GH, Gong H. Respiratory symptoms and lung function in habitual heavy smokers of marijuana alone, smokers of marijuana and tobacco, smokers of tobacco alone, and nonsmokers. Am Rev Respir Dis. 1987;135:209-16.

37. Bloom JW, Kaltenborn WT, Paoletti P, Camilli A, Lebowitz MD. Respiratory effects of non-tobacco cigarettes. Br Med J (Clin Res Ed). 1987;295:1516-8.

38. Polen MR, Sidney S, Tekawa IS, Sadler M, Friedman GD. Health care use by frequent marijuana smokers who do not smoke tobacco. West J Med. 1993;158: 596-601.

39. Taylor DR, Poulton R, Moffitt TE, Ramankutty P, Sears MR. The respiratory effects of cannabis dependence in young adults. Addiction. 2000;95:1669-77.

40. Aldington S, Williams M, Nowitz M, Weatherall M, Pritchard A, McNaughton A, Robinson G, Beasley R. Effects of cannabis on pulmonary structure, function and symptoms. Thorax. 2007;62:1058-63.

41. Tan WC, Lo C, Jong A, Xing L, Fitzgerald MJ, Vollmer WM, Buist SA, Sin DD, Vancouver Burden of Obstructive Lung Disease (BOLD) Research Group. Marijuana and chronic obstructive lung disease-a population-based study. CMAJ. 2009;180:814-20.

42. James W, Barnes N, Stone I. The prevalence and impact of cannabis smoking in clinical trials of COPD. ERJ. 2015;46:337. https://doi.org/10.1183/ 13993003.congres-s2015.PA337.

43. Tashkin DP, Simmons M, Tseng C-H. Impact of changes in regular use of marijuana and/or tobacco on chronic bronchitis. COPD. 2012;9:367-74.
44. Hancox RJ, Shin HH, Gray AR, Poulton R, Sears MR. Effects of quitting cannabis on respiratory symptoms. Eur Respir J. 2015;46:80-7.

45. Alberg AJ, Ford JG, Samet JM, American College of Chest Physicians. Epidemiology of lung cancer: ACCP evidence-based clinical practice guidelines (2nd). Chest. 2007;132:29S-55S.

46. Maertens RM, White PA, Rickert W, et al. The genotoxicity of mainstream and sidestream marijuana and tobacco smoke condensates. Chem Res Toxicol. 2009;22:1406-14.

47. Mehra R, Moore BA, Crothers K. The association between marijuana smoking and lung cancer: a systematic review. Arch Intern Med. 2006;166: 1359-67.

48. Moir D, Rickert WS, Levasseur G, et al. A comparison of mainstream and sidestream marijuana and tobacco cigarette smoke produced under two machine smoking conditions. Chem Res Toxicol. 2008;21:494-502.

49. Marselos M, Karamanakos P. Mutagenicity, developmental toxicity and carcinogenicity of cannabis. Addict Biol. 1999;4:5-12.

50. Tashkin DP, Baldwin GC, Sarafian T, Dubinett S, Roth MD. Respiratory and immunologic consequences of marijuana smoking. J Clin Pharmacol. 2002;42:71S-81S.

51. Barsky SH, Roth MD, Kleerup EC, Simmons M, Tashkin DP. Histopathologic and molecular alterations in bronchial epithelium in habitual smokers of marijuana, cocaine, and/or tobacco. J Natl Cancer Inst. 1998;90(16):1198-205. https://doi.org/10. 1093/jnci/90.16.1198.

52. Auerbach O, Stout AP, Hammond ED, Garfinkel L. Changes in bronchial epithelium in relation to cigarette smoking and its relation to lung cancer. N Engl J Med. 1961;265:253-67.

53. Fligiel SEG, Roth MD, Kleerup EC, Barsky SH, Simmons MS, Tashkin DP. Tracheobronchial histopathology in habitual smokers of cocaine, marijuana, and/or tobacco. Chest. 1997;112: 319-26.

54. Zhang LR, et al. Cannabis smoking and lung cancer risk: pooled analysis in the International Lung Cancer Consortium. Int J Cancer. 2015;136: 894-903.

55. Sidney S, Quesenberry CP Jr, Friedman GD, Tekawa IS. Marijuana use and cancer incidence (California, United States). Cancer Causes Control. 1997;8: 722-8. 
56. Callaghan RC, Allebeck P, Sidorchuk A. Marijuana use and risk of lung cancer: a 40-year cohort study. Cancer Causes Control. 2013;24:1811-20.

57. Sanchez C, de Ceballos ML, Gomez del Pulgar T, Rueda D, Corbacho C, Velasco G, Galve-Roperh I, Huffman JW, Ramon y Cajal S, Guzman M. Inhibition of glioma growth in vivo by selective activation of the CB2 cannabinoid receptor. Cancer Res. 2001;61:5784-9.

58. Olea-Herrero N, Vara D, Malagarie-Cazenave S, Diaz-Laviada I. Inhibition of human tumour prostate PC-3 cell growth by cannabinoids R(1)methanandamide and JWH-015: involvement of CB2. Br J Cancer. 2009;101:940-50.

59. Vara D, Salazar M, Olea-Herrero N, Guzman M, Velasco G, Diaz- LI. Anti-tumoral action of cannabinoids on hepatocellular carcinoma: role of AMPK-dependent activation of autophagy. Cell Death Differ. 2011;18:1099-111.

60. Llewellyn CD, Linklater K, Bell J, Johnson NW, Warnakulasuriya S. An analysis of risk factors for oral cancer in young people: a case- control study. Oral Oncol. 2004;40:304-13.

61. Llewellyn CD, Johnson NW, Warnakulasuriya AAS. Risk factors for oral cancer in newly diagnosed patients aged 45 years and younger: a case-control study in southern England. J Oral Pathol Med. 2004;33:525-32.

62. Sidney S, Beck JE, Tekawa IS, Quesenberry CP, Friedman GD. Marijuana use and cancer incidence. Am J Public Health. 1997;87:585-90.

63. Aldington S, Harwood M, Cox B, Weatherall M, Beckert L, Hansell A, Pritchard A, Robinson G, Beasley R, Cannabis and Respiratory Disease Research Group. Cannabis use and risk of lung cancer: a case-control study. Eur Respir J. 2008;31: 280-6.

64. Aldington S, Harwood M, Cox B, et al. Cannabis use and cancer of the head and neck: case-control study. Otolaryngol Head Neck Surg. 2008;138(3): 374-80. https://doi.org/10.1016/j.otohns.2007.12. 002.

65. Kim J, Hua G, Zhang H, Chan TJ, Xie M, Levin M, Farrokhyar F, Archibald SD, Jackson B, Young JE, Gupta M. Rate of second primary head and neck cancer with cannabis use. Cureus. 2020;12(11): e11483. https://doi.org/10.7759/cureus.11483.

66. Feng BJ, Khyatti M, Ben-Ayoub W, et al. Cannabis, tobacco and domestic fumes intake are associated with nasopharyngeal carcinoma in North Africa. Br J Cancer. 2009;101(7):1207-12. https://doi.org/10. 1038/sj.bjc.6605281.
67. Sidney S, Quesenberry CP Jr, Friedman GD, Tekawa IS. Marijuana use and cancer incidence (California, United States). Cancer Causes Control. 1997;8(5): 722-8. https://doi.org/10.1023/a:1018427320658.

68. Parker J, et al. Characteristics and 12-Week Outcomes for Marijuana Smokers in Subjects With Asthma Treated in the Emergency Department for an Asthma Exacerbation. Chest. 2012;142:733A. https://doi.org/10.1378/chest.1382146.

69. Decuyper II, Van Gasse AL, Cop N, et al. Cannabis sativa allergy: looking through the fog. Allergy. 2017;72:201e206.

70. Silvers W, Bernard T. Spectrum and prevalence of reactions to marijuana in a Colorado allergy practice. Lett Ann Allergy Asthma Immunol. 2017;119: $570-1$.

71. Tessmer A, Berlin N, Sussman G, et al. Hypersensitivity reactions to marijuana. Ann Allergy Asthma Immunol. 2012;108:282e284.

72. Kagen SL, Kurup VP, Sohnle PG, et al. Marijuana smoking and fungal sensitization. J Allergy Clin Immunol. 1983;71:389e393.

73. Silvers WS. A Colorado allergist's experience with marijuana legalization. Ann Allergy Asthma Immunol. 2016;116:175e177.

74. Cary RM, et al. Pleuritic chest pain and fluid levels on imaging in a heavy cannabis smoker. BMJ Case Rep. 2015. https://doi.org/10.1136/bcr-2014208064 .

75. Hashmi HR, Duncalf R, Khaja M. A case report of cannabis induced hemoptysis. Medicine (Baltimore). 2016;95(13): e3232. https://doi.org/10.1097/ MD.0000000000003232.

76. Beshay M, Kaiser H, Niedhart D, Reymond MA, Schmid RA. Emphysema and secondary pneumothorax in young adults smoking cannabis. Eur J Cardiothorac Surg. 2007;32(6):834-8. https://doi. org/10.1016/j.ejcts.2007.07.039.

77. Richman LS, Whitaker J, Kinnard WV. A case of acute hypersensitivity pneumonitis due to cannabis dabbing. Drug Induc Lung Dis Case Rep. 2018;1: A6636-A6636.

78. Natarajan A, Shah P, Mirrakhimov AE, Hussain N. Eosinophilic pneumonia associated with concomitant cigarette and marijuana smoking. BMJ Case Rep. 2013;2013:bcr013009001. https://doi.org/10. 1136/bcr-2013-009001.

79. Siddiqui F, Khan T, Siddiqui A, Weisel S. Lung pathology fellow case report poster-lung 
pathology. Chest J. 2016;150(4):783. https://doi. org/10.1016/j.chest.2016.08.879.

80. Golwala H. Marijuana abuse and bullous emphysema. Lung India Indian Chest Soc. 2012;29(1): 56-8.

81. Van Landeghem A, Arys B, Heyse C, Gosselin R. Lung emphysema caused by marijuana smoking. JBR-BTR. 2012;95:166-7.

82. Tashkin DP. Smoked marijuana as a cause of lung injury. Monaldi Arch Chest Dis. 2005;63:93-100.

83. Gargani Y, Bishop P, Denning DW. Too many mouldy joints-marijuana and chronic pulmonary aspergillosis. Mediterr $\mathrm{J}$ Hematol Infect Dis. 2011;3(1): e2011005. https://doi.org/10.4084/ MJHID.2011.005.

84. Kagen SL, Kurup VP, Sohnle PG, Fink JN. Marijuana smoking and fungal sensitization. J Allergy Clin Immunol. 1983;71:389-93. https://doi.org/10. 1016/0091-6749(83)90067-2.

85. Mittleman MA, Lewis RA, Maclure M, Sherwood JB, Muller JE. Triggering myocardial infarction by marijuana. Circulation. 2001;103(23):2805-9.

86. Aronow W, Cassidy J. Effect of smoking marihuana and of a high-nicotine cigarette on angina pectoris. Clin Pharmacol Ther. 1975;17(5):549-54.

87. Petronis KR, Anthony JC. An epidemiologic investigation of marijuana- and cocaine-related palpitations. Drug Alcohol Depend. 1989;23(3):219-26.

88. Singhm GK. Atrial fibrillation associated with marijuana use. Pediatr Cardiol. 2000;21(3):284.

89. Kosior DA, Filipiak KJ, Stolarz P, Opolski G. Paroxysmal atrial fibrillation following marijuana intoxication: a two-case report of possible association. Int J Cardiol. 2001;78(2):183-4.

90. Rezkalla SH, Sharma P, Kloner RA. Coronary noflow and ventricular tachycardia with habitual marijuana use. Ann Emerg Med. 2003;42(3):365-9.

91. Cooles P, Michaud R. Stroke after heavy cannabis smoking. Postgrad Med J. 1987;63(740):511.

92. Zachariah SB. Stroke after heavy marijuana smoking. Stroke. 1991;22(3):406-9.

93. Barnes D, Palace J, O’Brien MD. Stroke following marijuana smoking. Stroke. 1992;23(9):1381.

94. Mouzak A, Agathos P, Kerezoudi E, Mantas A, Vourdeli-Yiannakoura E. Transient ischemic attack in heavy cannabis smokers-how 'safe' is it? Eur Neurol. 2000;44(1):42-4.
95. Nahas GG. Cannabis arteritis. N Engl J Med. 1971;284(2):113.

96. Disdier P, Granel B, Serratrice J, et al. Cannabis arteritis revisited-ten new case reports. Angiology. 2001;52(1):1-5.

97. Aryana A, Williams D. Marijuana as a trigger of cardiovascular events: speculation or scientific certainty? Int J Cardiol. 2007;118:141-4.

98. Owen KP, Sutter ME, Albertson TE. Marijuana: respiratory tract effects. Clin Rev Allergy Immunol. 2014;46(1):65-81. https://doi.org/10.1007/s12016013-8374-y.

99. Eissenberg T, Shihadeh A. Waterpipe tobacco and cigarette smoking: direct comparison of toxicant exposure. Am J Prev Med. 2009;37:518-23.

100. Shihadeh A, Schubert J, Klaiany J, El Sabban M, Luch A, Saliba NA. Toxicant content, physical properties and biological activity of waterpipe tobacco smoke and its tobacco-free alternatives. Tob Control. 2015;24(Suppl 1):i22-30.

101. Van Dam NT, Earleywine M. Pulmonary function in cannabis users: support for a clinical trial of the vaporizer. Int J Drug Policy. 2010;21:511-3.

102. He T, Oks M, Esposito M, Steinberg H, Makaryus M. Tree-in-bloom": severe acute lung injury induced by vaping cannabis oil. Ann Am Thorac Soc. 2017;14(3):468-70. https://doi.org/10.1513/ AnnalsATS.201612-974LE.

103. Malouff JM, Rooke SE, Copeland J. Experiences of marijuana-vaporizer users. Subst Abuse. 2014;35: 127-8.

104. Earleywine M, Barnwell SD. Decreased respiratory symptoms in cannabis users who vaporize. Harm Reduct J. 2007;4:11.

105. Tashkin D. How beneficial is vaping cannabis to respiratory health compared to smoking? Addiction. 2015;110:1705-11.

106. https://www.cdc.gov/tobacco/basic_information/ecigarettes/severe-lung-disease.html. Accessed 13 July 2021

107. Aldington $\mathrm{S}$, et al. Effects of cannabis on pulmonary structure, function and symptoms. Thorax. 2007;62:1058-63. https://doi.org/10.1136/thx. 2006.077081 .

108. https://www.cdc.gov/tobacco/basic_information/ecigarettes/severe-lung-disease.html. Accessed 13 July 2021 